\title{
RELAÇÃO PÚBLICO-PRIVADA E PRECARIZAÇÃO DO TRABALHO: UM ENSAIO TEÓRICO
}

João Gomes Moreira, Fernanda Aparecida Augusto, Irene da Caires da Silva, Maria Elisa Nogueira Oliveira, Tatiana Veiga Uzeloto

Universidade do Oeste Paulista - UNOESTE. E-mail: ig.moreira@yahoo.com.br

\section{RESUMO}

Este artigo tem o objetivo de discutir o desmanche que as propostas neoliberais vêm realizando com relação às políticas sociais, que o Estado, em cumprimento ao seu dever, deveria providenciar, visando ao bem estar da população, numa postura democrática. Buscou-se esclarecer que a relação público-privada nada mais é que uma grande estratégia do capital para criar e ampliar novos nichos de mercado para a superação da crise cíclica do capitalismo, sempre apresentada com novas roupagens nas mutações que se processam, para reduzir os efeitos da inevitável asfixia social que acabou por gerar grandes revoluções registradas em seu processo histórico. O presente artigo é de cunho bibliográfico, onde buscou-se informações em doutrinas, periódicos, revistas especializadas, sites oficiais, dentre outros. Por fim, mostrou-se um diagnóstico breve da atual situação da educação pública brasileira que, a partir da terceira via, vem incorporando novas formas de atuação pautadas na lógica do mercado.

Palavras-chave: Precarização do Trabalho; Relação Público-Privada; Educação Básica.

\section{PUBLIC-PRIVATE RELATIONSHIP AND PRECARISATION OF WORK: A THEORETICAL TEST}

\begin{abstract}
This article aims to discuss the dismantling that the neoliberal proposals have been making in relation to social policies, which the State, in fulfillment of its duty, should provide for the wellbeing of the population, in a democratic way. It was sought to clarify that the public-private relationship is nothing more than a major strategy of capital to create and expand new market niches to overcome the cyclical crisis of capitalism, always presented with new clothes in the mutations that are processed, to reduce the effects of the inevitable in the social asphyxiation that eventually generated great revolutions recorded in its historical process. This article is of bibliographic character, where information was sought in doctrines, periodicals, specialized magazines, official websites and others. Finally, it was a brief diagnosis of the current situation of the Brazilian public education that, from the third way, has been incorporating new forms of action based on the logic of the market.
\end{abstract}

Keywords: Precariousness of Work; Public-Private Relationship; Basic education. 


\section{INTRODUÇÃO}

As políticas implementadas pelo governo Fernando Henrique Cardoso (FHC), mais propriamente através do documento intitulado "Plano Diretor da Reforma do Aparelho do Estado" (BRASIL, 1995), visaram ao atendimento das pressões de organismos internacionais e do mercado, por meio de mecanismos atenuadores da crise cíclica do capitalismo vistos como "estratégias de superação", conhecidos por "neoliberalismo", "globalização", "reestruturação produtiva" e "terceira via". (PERONI, p.1, s/d)

O Estado, segundo a visão neoliberal, é responsável pela crise estrutural que aflige a sociedade, devido à sua interferência na política econômica e sua participação no processo de distribuição de renda considerada paternalista. (SINGER, 1996). Ainda nesta óptica, o Estado deveria concentrar-se em fortalecer-se na função de promotor e regulador desse desenvolvimento na produção de bens e serviços, via relação público-privada, em que as atividades são transferidas para a iniciativa privada. (PERONI, p.2, s/d)

O Plano de Reforma do Estado no Brasil propõe que as empresas públicas sejam privatizadas ou transformadas em organizações sociais, organizações parceiras do Estado não dirigidas pelo poder público, mas recebendo fundos públicos. (PERONI, p.4, s/d)

Essas mudanças passam pela redução no papel do Estado, cujo ofício passa a ser o da racionalização dos recursos, sacrificando a sociedade, com a redução de políticas de assistência social. Segundo Bresser Pereira (1998), nesta lógica as organizações se tornam mais eficientes, flexíveis e competitivas, atendendo melhor aos anseios da sociedade e melhorando a qualidade da oferta dos serviços públicos, dentre eles, a educação. Este discurso vem sendo cada vez mais reforçado pelo Banco Mundial, conforme podemos observar na leitura do recente relatório "Um ajuste justo" publicado em 2017, cujas recomendações se voltam à intensificação da privatização das instituições públicas, que passariam a cobrar pelos serviços educacionais, ferindo os direitos adquiridos pelas lutas sociais.

$\mathrm{O}$ artigo em questão tem como objetivo principal discutir o desmanche que as propostas neoliberais vêm realizando com relação às políticas sociais, que o Estado, em cumprimento ao seu dever, deveria providenciar, visando ao bem estar da população, numa postura democrática.

\section{METODOLOGIA}

Este artigo apresenta um estudo bibliográfico construído com base em informações coletadas em periódicos, revistas especializadas e sites oficiais. Sua natureza é exploratória, viabilizando as discussões sobre a temática principal, que versa sobre as relações público-privadas, e a educação.

De acordo com Lakatos (apud ANDER - EGG, 1978, p.28), a pesquisa é um "procedimento reflexivo sistemático, controlado e crítico, que permite descobrir novos fatos ou dados, relações ou leis, em qualquer campo do conhecimento".

Por fim, o presente artigo, elabora uma reflexão, que cria um caminho para conhecermos a realidade na qual estamos inseridos.

\section{RESULTADO}

A relação público-privada acontece no apogeu da crise do capitalismo, que, anteriormente à sua expansão, no pós-guerra, buscava nela uma estratégia eficaz para ampliar as possibilidades de saídas para tal colapso. Durante o chamado "período de acumulação de capitais", mais precisamente nos anos 70 , em que se registrou a crise da estrutura do capitalismo ${ }^{1}$ e o

\footnotetext{
1 “A crise capitalista não é outra coisa senão a ruptura de um padrão de dominação de classe relativamente estável. Aparece como uma crise econômica, que se expressa na queda da taxa de lucro, Seu núcleo, entretanto, é marcado pelo fracasso de um padrão de dominação estabelecido [...]. Para o capital, a crise somente pode encontrar sua resolução através da luta, mediante o estabelecimento da autoridade e através de uma difícil busca de novos padrões de dominação. (HOLLOWAY, 1987, p. 132 apud ANTUNES, 1999, p.31)
} 
esgotamento da acumulação proporcionada pelo regime fordista, o Estado modificou sua função e criou espaços para a atuação do sistema privado, afetando, em profundidade, as políticas sociais ${ }^{2}$.

No contexto de crise do capitalismo, em especial nos anos de 1990, no Brasil, foram introduzidos mitos, que segundo Pochmann (2001), não diferem da propaganda nazista, pois, comprovadamente, foram introduzidos com base em invenções, com o claro objetivo de criar uma unidade na opinião pública em torno de ideias neoliberais, que cristalizaram verdades absolutas. Para o autor, o período pode ser definido como "a década dos mitos".

O primeiro mito surge da constatação de que o esvaziamento do papel do Estado levaria o país ao crescimento econômico sustentado, com elevação do nível de ocupação. Por meio da privatização seria possível reduzir o endividamento público e aplicar o gasto social, deixando ao setor privado o comando da expansão econômica. (POCHMANN, 2001, p.8)

Para colocar em vigência políticas voltadas à demanda do mercado, foram implementadas as medidas de ajuste fiscal, propostas pelo Banco Mundial e seus organismos, exigiam

[...] a reavaliação do papel do Estado e a aprovação das reformas no setor público [...] novas ações convergentes para o aumento da descentralização das atribuições de competências operacionais do Estado, com a introdução de mecanismos de mercado e competição administrada, através da privatização de seguimentos estatais em setores produtivos. (POCHMANN, 2001, p.16)

Muitos ajustes foram sendo realizados pela via da privatização, com o objetivo de garantir atendimento mínimo às demandas sociais. O Estado passou a ser somente um regulador das estratégias de acumulação do capital, seguindo à lógica do mercado. Ao conjugar a relação entre a esfera pública e privada, o Estado passa a ganhar novos contornos, não apenas transferindo ao empresariado parte de suas funções, "mas também para o público não-estatal a execução das políticas, ou ainda mudando a lógica de gestão do público, tendo como parâmetro o privado". (PERONI; OLIVEIRA; FERNANDES, 2009, p. 762). Com base no discurso da "competência", "eficiência" e "produtividade", a gestão pública passa a assumir um caráter gerencial, enfraquecendo a gestão democrática no setor educacional, conquistada a duras penas pelos movimentos sociais.

\section{DISCUSSÃO}

Segundo Mészáros (2008), a crise não se encontra no Estado, é uma crise estrutural do próprio capital que, dentro da perspectiva e da teoria neoliberal, seria superada na redução do Estado por meio de reformas e da diminuição de sua ação em políticas públicas.

A função de restaurador do equilíbrio das ações errôneas realizadas pelo poder público é atribuída ao mercado que, em regime de "parcerias", passa a "contribuir" com a oferta de serviços públicos, cobrando, para isso, incentivos fiscais bilionários que reduzem a arrecadação, criando um cenário de dependência cada vez mais difícil de ser superado. Sob o discurso de que as políticas sociais são consideradas um verdadeiro saque à propriedade privada, pois além de distribuírem renda, atrapalham o livre andamento do mercado, na medida em que os impostos oneram a produção, os grandes grupos financeiros e empresariais vão ampliando seu espaço de atuação, ofertando o mínimo e lucrando o máximo possível. (PERONI; OLIVEIRA, FERNANDES, 2009, p. 764).

\footnotetext{
2 "Assumindo o teto dos gastos públicos adotados em dezembro de 2016 como lei pétrea, o relatório calcula as medidas necessárias para efetivamente desempenhar este corte. Segundo o Banco Mundial, sua implementação exigirá "redução dos gastos em cerca de $06 \%$ do PIB ao ano em relação à tendência atual durante a próxima década". Esses cortes atingirão, em especial, segundo dados, a "seguridade social, saúde, educação, gestão de pessoas, etc. O setor educacional, dentre outros, terá as seguintes medidas perversas: "acabar com a gratuidade das universidades, extinguir a vinculação institucional dos gastos em educação a $25 \%$ das receitas dos municípios, aumentar a quantidade de estudantes por sala de aula, e diminuir o número de escolas públicas". Disponível em: http://178.62.201.127/noticia/o-relatorio-do-banco-mundiale-o-futuro-do-brasil
} 
O objetivo do mercado se torna a busca pelo lucro frenético e desumanizador, por meio de um processo de mercantilização da sociedade, cujo resultado é o aumento da disparidade social. No que tange à terceira via, sua proposta, apesar da roupagem democrática, assemelha-se à proposta do neoliberalismo ao ocultar os verdadeiros interesses voltados ao atendimento da demanda do mercado.

De acordo com o professor Luiz Carlos de Freitas, em matéria publicada em seu Blog, os conglomerados empresarias articulam leis que fundamentam seus interesses em vista de seus investimentos, desconsiderando a questão democrática e incentivando a privatização da educação em todos os níveis. Esta será, portanto, a grande batalha que se seguirá, sugando recursos públicos e precarizando ainda mais a educação pública e o trabalho docente conforme veremos no tópico a seguir. ${ }^{3}$

No que se refere ao processo de precarização do trabalho, podemos trazer à tona os grandes prejuízos causados pelas políticas neoliberais à classe trabalhadora, neste caso, 0 profissional docente. Suas condições de trabalho, cada dia mais precarizadas, devido à ausência de políticas de proteção social, deixam a categoria à mercê de um sistema que a adoece. As medidas que tomaram e vem tomando o governo atual, para Frigotto e Ciavatta (2003), é uma afronta à classe trabalhadora em suas lutas por direitos sociais. Medidas que visam atender ao mercado privatista vão na contramão de tudo que se pode conceber sobre educação. $O$ atual governo de Michel Temer traz propostas que afligem a classe do professorado e, segundo Frigotto, torna a educação totalmente dependente da fração do capital. Uma política que flexibiliza o trabalho, por meio de parcerias público-privadas, reduz a qualidade do ensino ofertado aos filhos dos trabalhadores. Aos professores são dadas cada vez mais condições mínimas de sobrevivências com salários e condições laborais, se não desumanas, precarizadas. Diferentemente do que o filósofo István Mészáros defendia ao afirmar que o processo de "educar não é a mera transferência de conhecimentos, mas sim conscientização e testemunho de vida. É construir, libertar o ser humano das cadeias do determinismo neoliberal, reconhecendo que a história é um campo aberto de possibilidades". (MÉSZÁROS, 2008, p.13)

Neste sentido, conforme apontam Ramos e Frigotto (2017), neste cenário atual de contrarreformas, é necessária a retomada das lutas sociais, por vias de organizações trabalhistas, em prol da escola pública e a intensificação, dentro da luta de classes, de uma ação prepositiva de outros segmentos com iniciativas contra as forças do capital que perpassam todo o processo histórico criando e usando o saber para os interesses do mercado que, para Frigotto e Civiatta (2003), condicionam a educação ao trabalho, limitando sua ação na totalidade da vida integral da classe trabalhadora. Por isso, a importância de "buscar forças organizadas de amplos setores da sociedade para, aprendendo das lutas de resistências do passado, resistir no todo e no detalhe a seus intentos" (RAMOS; FRIGOTTO, 2017, p.31).

Não se pode perder de vista as conquistas realizadas no plano educacional, que asseguraram à classe trabalhadora formação integral. Por isso, faz-se imprescindível, conforme se fez no passado, congregar

[...] milhares de pesquisadores e educadores de todo o país não apenas para contestar as propostas inspiradas no credo neoliberal, mas para afirmar a concepção de educação e de seu financiamento e organização convergentes com os interesses da classe trabalhadora. (RAMOS; FRIGOTTO, 2017, p.36)

Desta maneira, não se pode perder a resistência, deve-se lutar, em conjunto, contra o sistema excludente que faz da educação, um nicho de mercado e, como afirma Freitas (2012), um projeto do empresariado para precarizar a escola pública.

\footnotetext{
${ }^{3}$ Referência à matéria "Ensino Básico: o mercado se prepara e nós?”, publicada no Blog Avaliação Educacional, do professor Luiz Carlos de Freitas, em 21 de abril de 2018. Disponível em: https://avaliacaoeducacional.com/2018/04/21/ensino-basico-o-mercado-se-prepara-e-nos/ Acesso em 10 de set. de 2018.
} 


\section{CONCLUSÃO}

A proposta deste artigo foi buscar entender como se processa a relação público-privada na educação e de onde vem essa força do capital que penetra todas as instâncias do poder público.

Os autores que serviram de subsídio teórico, permitiram apresentar um breve diagnóstico da atual situação da educação pública brasileira que, a partir da terceira via, vem incorporando novas formas de atuação pautadas na lógica do mercado.

Por fim, observou-se a influência das relações público-privadas na precarização do trabalho docente e buscou-se apontar como horizonte a retomada das lutas sociais em defesa da escola pública.

\section{REFERÊNCIAS}

ANDER-EGG. Introducción a las técnicas de investigación social: para trabajadores sociales. 7. ed. Buenos Aires: Humanitas, 1978.

ANTUNES, Ricardo. Adeus ao trabalho? São Paulo: Cortez, 2006.

BRASIL. Presidência da República. Câmara da Reforma do Estado. Plano Diretor da Reforma do Aparelho do Estado. Brasília, 1995. Disponível em: http://www.bresserpereira.org.br/documents/mare/planodiretor/planodiretor.pdf Acesso em: 10 de set. de 2018.

BRESSER PEREIRA, L. C. A reforma do estado dos anos 90: lógica e mecanismos de controle. Lua Nova [online]. 1998, no 45, pp.49-95. Disponível em: http://www.bresserpereira.org.br/documents/MARE/CadernosMare/CADERNO01.pdf Acesso em: 10 set., 2018.

FREITAS, Luiz Carlos. Agenda dos reformadores empresarias pode destruir a educação Pública no Brasil. Revista Adusp. São Paulo, Out. 2012. Disponível em: https://www.adusp.org.br/files/revistas/53/mat01.pdf

FRIGOTTO, Gaudêncio; CIAVATTA, Maria. Educar o trabalhador produtivo ou o ser humano emancipado? Trabalho, Educação e Saúde. 2003. p.45-60.

RAMOS, Marise Nogueira; FRIGOTTO, Gaudêncio. "Resistir é preciso, fazer não é preciso": as contrarreformas do ensino médio no Brasil. Cadernos de pesquisa em Educação - PPGE/UFES, $p$. 26-47, jul./dez.2017.

MÉSZÁROS, István. Educação para além do capital. São Paulo: Boitempo, 2008.

PERONI, Vera Maria Vidal. Implicações da Relação Público-Privada para a Democratização na Educação. Reunião Científica da ANPED. 24 A 27 de julho de 2016/ UFPR - Curitiba/Paraná.

PERONI, Vera Maria Vidal. Reforma do Estado e a tensão entre público e privado. Disponível em : http://www.redefinanciamento.ufpr.br/antigo/vera2.pdf . Acesso em: 03 de junho de 2018.

PERONI, Vera Maria Vidal; OLIVEIRA, Regina Tereza Cestari de; FERNANDES, Maria Dilnéia Espíndola. Estado e Terceiro Setor: As novas regulações entre o público e o privado na gestão da educação básica brasileira. Educ. Soc., Campinas, vol.30, n.108. p. 761-778, out. 2009. 
POCHMANN, Márcio. A década dos mitos. São Paulo: Pinsy Ltda., 2001.

SINGER, Paul. Poder, política e educação. Revista Brasileira de Educação, no1, jan./fev./mar./abril, 1996. p. 5-15. 